\title{
Los delegados gubernativos militares (de la provincia de Alicante) durante la dictadura de Primo de Rivera
}

\author{
juan Francisco Pérez Ortiz *
}

Como parte de la memoria de licenciatura que sobre la evolución política de la provincia de Alicante estoy terminando en estos momentos, realicé una primera aproximación a la figura de los delegados gubernativos, su labor y su evolución. Aunque sería aventurado efectuar afirmaciones demasiado categóricas, creo que está por hacer un estudio en profundidad que permita un acercamiento satisfactorio a estos delegados y responda a una serie de hipótesis que se ha planteado. Como señalaba Ballvé en 1983, los fenómenos que se generaron en torno a los delegados no han sido suficientemente considerados, cuando podrían desvelar una buena cantidad de claves respecto al desarrollo de la Dictadura y a la actitud que los militares mantuvieron en los años siguientes. Quisiera aquí exponer las inquietudes y las preguntas que esta aproximación ha suscitado y que espero poder estudiar más adelante.

Primo de Rivera necesitaba hacer efectiva, en todos los rincones del país, la presencia de su poder, si pietendía que fuese realmente transformador de la vida política. Con tal fin creó una figura, la de los delegados gubernativos, concebidos como ejecutores de las medidas de saneamiento dictadas para regenerar la nación. La orientación básica de este novedoso instrumento - llevar el poder de manera efectiva a todo el país - era acertada y podía haber rendido buenos resultados en otras circunstancias y con otros representantes.

\footnotetext{
* Universidad de Alicante.
} 
La respuesta del estamento militar ante el nuevo destino que se les ofrecía fue inmediata, la que no se extrañó si se tiene en cuenta que previamente se había autorizado a los gobernadores "cívico-militares» a utilizar oficiales en las inspecciones que abundaron en los primeros momentos de la Dictadura. La necesidad de la actuación urgente de los delegados fue sentida por Bermudez de Castro, quien tras las primeras semanas de contacto con la realidad administrativa y política provincial se dirigió a Martínez Anido en estos preocupados términos:

\begin{abstract}
Afectada esta provincia de infección de inmoralidad en grado agudo, recibo diariamente denuncias de casi la totalidad de los pueblos. No tengo delegados suficientes acudir todos pueblos pues será raro aquel en que no haya grandes irregularidades. Espero con ansia delegados gubernativos para cuanto antes empezar labor moralizadora y de castigo ${ }^{1}$.
\end{abstract}

Los delegados constituirían, dentro de la estrategia regenercionista, el puente que enlazaría con la promulgación de la nueva ley municipal. No eran en definitiva mas que la proyección de Primo de Rivera a nivel local, proporcionando la cercanía decisiva para atacar las estructuras caciquiles. El fuerte impulso inicial que recibieron, con múltiples disposiciones e instrucciones, refleja la importancia que se les atribuyó.

Aunque su tarea fundamental consistiría en la inspección y orientación de las funciones municipales, se les encargó también una serie muy amplia de misiones, que en general estaban orientadas a desarrollar el espíritu de ciudadanía. La descripción más detallada de los aspectos de la vida municipal que debían vigilar se les facilitó a comienzos de diciembre ${ }^{2}$.

La labor de los delegados fue planteada en términos míticos. Se les encarecía el celo en su obra puesto que de ellos dependía "hacer una nueva Patria». Sin duda, para muchos esta tarea excedía sus cualidades, pero les infundió un concepto reverencial, sacralizado, de sí mismos. Carecían de la preparación mínima necesaria, a nivel general y sobre la zona a la que eran destinados, lo que mermaba desde el principio su posible eficacia. Enviados como apóstoles de la nueva fe patriotera y

AHN, MG, leg. 17-A. El telegrama data del 2-XI-1923.

${ }^{2}$ Gaceta, 9-XII-1923; "Prevenciones que para el mejor desempeño de sus cargos deben tener presentes los Delegados gubernativos", 7-XII-1923, AHN, MG, leg. 17-A. 
regeneracionista, no se podía ocultar la concepción simplista, paternal y militarista de su misión.

El número de delegados en activo y sus atribuciones variaron notablemente durante la Dictadura. Es fácil reconstruir a grandes rasgos lo que podríamos considerar la actuación arquetípica de los delegados durante su primera etapa. Lamentablemente es mucho más difícil localizar las cartas e informes que enviaban con frecuencia al Gobierno Civil. El factor más destacable reside en su ignorancia sobre la complejidad de las relaciones políticas anteriores al golpe de estado y sobre los actores de esa política. Debían combatir al caciquismo, arrinconando a sus representantes dependiendo para ello de las fuentes que les facilitaran información sobre personas independientes o "apolíticas", al tiempo que se producían movimientos de camuflaje y aproximación por parte de las estructuras caciquiles. Dado que era normal que no existiese un sólo hombre neutral en política (ni sacerdotes, ni miembros de la Guardia Civil) es de suponer que los delegados estuvieron a merced de aquellos en quienes inicialmente depositaran su confianza.

Sin embargo, hay autores que afirman que los delegados encontraron en la justicia municipal su adversario más grave. Cuando menos no encontraron la cooperación que era de esperar.

La actuación en general de los delegados estuvo estrechamente vigilada y dirigida por los gobernadores. En las sucesivas reducciones se haría especial hincapié en la obediencia que los delegados debían a los gobernadores. Con frecuencia los delegados se limitaban a transmitir las órdenes o las convocatorias (a alcaldes o jefes de las Uniones Patrióticas) que partían de la capital provincial, actuando como meros intermediarios.

A partir de mayo de 1924 tuvieron como ocupación preferente la formación de somatenes y núcleos del naciente partido, la Unión Patriótica, con lo que aún adquirió mayor relieve su función de selectores del personal político. Desde estos momentos las tareas de fiscalización irían perdiendo importancia y empuje. Prestarían mayor atención a sancionar los comportamientos públicos 0 a organizar fiestas patrióticas de todo tipo. Quienes habian de jugar un papel esencial en la regeneración del país se estaban convirtiendo en censores de la moral pública. Se produjo así un cambio cualitativo que supuso una pérdida del peso específico de los delegados en la vida de los pueblos, aunque conservarían buena parte de su influencia. El impacto psicológico que pudo provocar el anuncio de su labor fiscalizadora a finales de 1923 se había atenuado indudablemente un año después. 
Durante este tiempo habían recibido el encargo de nuevas misiones: vigilancia de la confección del censo electoral, fomento de la creación de pósitos, inspección de la enseñanza primaria, ejercicio de la censura de prensa...

En este primer período hay que subrayar el conflicto protagonizado por el delegado del partido judicial de Dolores, que conocemos a través de un voluminoso expediente ${ }^{3}$. Los detalles de este caso ofrecen una información de primera calidad sobre múltiples cuestiones, destacando las declaraciones del delegado. Se advierte en esas declaraciones un fondo de amargura y despecho considerable contra los "políticos" (que cargaron con maestría y maquiavelismo contra él). Probablemente, su vuelta al cuartel, como la de otros muchos que dieron lugar a destituciones, se acompañó de un profundo escepticismo y resentimiento contra la sociedad civil, junto con un sentido derrotista de la capacidad de los civiles para gobernar y hacer prosperar el país. En el terreno de las hipótesis deberíamos plantearnos si el apoliticismo que propugnaba el régimen se transformó en estos delegados en una repulsión instintiva contra la política, si difundieron este sentimiento entre sus compañeros y en consecuencia, contribuyeron a un mayor desarrollo de la conciencia intervencionista dentro del ejército.

La evidencia de que muchos delegados se sintieron complacidos con su poder y tentados de ejercerlo sin cortapisas nos es ofrecida por Calvo Sotelo al comentar la primera restricción importante que tuvieron de sus funciones: «Pasaron bastantes meses sin que el espíritu de esta Real orden ganase formal acatamiento". En muchas provincias es posible que los delegados se limitasen, tras esta y tras las siguientes reducciones, a ejercer las funciones que se les asignaban, pero en la provincia de Alicante (y habría que estudiar profundamente en qué otras provincias) no ocurrió así en absoluto. No ha de extrañarnos que la idea medular de las nuevas disposiciones fuese la de una completa y absoluta subordinación a los gobernadores civiles, junto a la separación de los delegados de zonas concretas en las que actuasen exclusivamente.

En Alicante el rasgo característico a partir de 1927 va a ser la intervención en los conflictos obreros, que se intensificaron desde este año (la radicalización de una de estas huelgas exigió la intervención personal de Primo de Rivera). Los delegados estuvieron constantemente ocupados como enviados del gobernador, jugando un papel de negociadores y con-

${ }^{3}$ AHN, PG, leg. 62. 
ciliadores entre obreros y patronos, que no conocemos con gran detalle: ¿eran meros transmisores de órdenes del gobernador o gozaban de autonomía y capacidad de iniciativa para presionar a ambas partes? Lo que parece indudable es que gozaban de una confianza total por parte de los distintos gobernadores.

Cuando se anunció la última reducción, los gobernadores expusieron una serie de razones para que se permitiese permanecer a más de un delegado en sus respectivas provincias. El conjunto de estos motivos constituye un mosaico que casi representa una radiografía de la situación política del país. Respecto a Alicante se decía:

Además de los muchos pueblos que tiene la provincia, las modalidades especiales de algunos de ellos como los puertos de mar, en donde el tráfico e industria requieren atenciones y vigilancia especial. El número considerable de obreros por las industrias existentes en Alcoy, Elche, Crevillente, Novelda, Cocentaina, etc., muy levantiscos y rebeldes; las comunidades de labradores y regantes en la parte de la huerta, que producen graves complicaciones constantes. Vigilancia de la administración municipal.

El Negociado de Reclamaciones que se había creado poco antes y que se encargó ahora a los delegados, se limitaba a recoger y orientar las quejas de los ciudadanos, sin tener asignado ningún tipo de capacidad ejecutiva. Si los delegados de una provincia eran destinados a estos negociados en exclusiva, sí que podríamos afirmar que la institución era prácticamente aniquilada. En caso contrario se abría la etapa más interesante, más desconocida y tal vez, con repercusiones posteriores más importantes.

A la hora de efectuar un balance de su gestión debemos tomar en cuenta múltiples factores. Su particular posición en la cadena del poder ejecutivo, como órgano intermediario, les llevó ineludiblemente a convertirse en gestores de las demandas de sus territorios ante el poder central. En algunos casos se produjeron iniciativas de indudable interés, que reflejaban una cierta sensibilidad para comprender las carencias y los problemas de los núcleos locales con menores recursos.

La combinación entre esta capacidad para intervenir como gestores, su papel como selectores del personal político y la permanencia durante toda la Dictadura de dos delegados apunta la posibilidad de que se viesen tentados de estructurar redes de poder, más o menos similares a las caciquiles. Contamos con indicios suficientes que apoyan esta hipótesis. 
Si bien un caso corresponde a uno de los delegados que permanece hasta el final, conocemos otro de un delegado que muy tempranamente dejó de serlo. Se dan una serie de importantes coincidencias: ambos delegados ejercen la "política" como influencia personal, ambos la mantienen con posterioridad a la pérdida de su destino efectivo y en ambos se transmite una dramática impotencia de los gobernadores para hacerse obedecer por los delegados y para limitar su influencia una vez que ha sido denunciada.

Si los delegados disfrutaron al comienzo de un poder excesivo en algunos campos (aunque se les recomendase tempranamente no extremar su actuación), pronto su capacidad real de maniobra se vio recortada y sufrieron un proceso de burocratización y anquilosamiento del que fueron en parte responsables los propios delegados.

La idea esencial que los sostenía, así como a Primo de Rivera, se basaba en la creencia mesiánica de la capacidad de transformación que sobre el país podían ejercer las personas adecuadas, de recto proceder y mano firme frente a los desmanes y abusos de los malos políticos. Los problemas a los que se tuvieron que enfrentar eran mucho más complicados y difíciles de solucionar de lo que simplistamente quisieron creer estos militares. Se les encomendaron un número excesivo de funciones, lo suficientemente imprecisas y ambiguas para que descuidasen o delegasen muchas de ellas y para que se extralimitasen con frecuencia. Como resultado cosecharon el odio de la población y generaron malestar en aigún sector del ejército.

Independientemente de los efectos de su actuación sobre el país se produjo un fenómeno radicalmente importante, que ya hemos apuntado en parte, relacionado con la actitud de estos militares y del conjunto de las fuerzas armadas: la politización de un amplio sector de la oficialidad, que se vio inmersa en los mecanismos de lucha por el poder a nivel local. $Y$ que en algunos casos dio lugar a la creación de un caciquismo de nueva factura, del que prácticamente todo está por descubrir. 